\title{
PIERRE HADOT E MICHEL FOUCAULT: SOBRE A FELICIDADE ESTOICA E A EXPERIÊNCIA DA ALEGRIA
}

PIERRE HADOT AND MICHEL FOUCAULT: ON THE STOIC HAPPINESS AND THE EXPERIENCE OF JOY

Cassiana Lopes Stephan*

\section{RESUMO}

Conforme Hadot, Foucault teria transformado a moral estoica em uma ética que busca o prazer em si mesmo, já que, erroneamente, conceberia a felicidade como um estado de puro deleite corpóreo e psíquico. Hadot afirma que para os estoicos a busca pela felicidade é incondicional, e a tranquilidade d'alma deve ser compreendida como um estado imperturbável no qual o si mesmo se encontra despojado de qualquer tipo de sentimento, seja ele violento ou sereno. Diferentemente, Foucault concebe que o domínio de si corresponde à soberania exercida sobre si mesmo e está atrelada a uma satisfação que se tem consigo. O estado de ataraxia ou euthumía é interpretado por Foucault como uma forma outra de prazer, aquela que se opõe ao prazer violento, cuja origem não está em nós mesmos, mas nos objetos aos quais descontroladamente atribuímos valores morais. Foucault associa essa diferenciação entre o mau e o bom prazer respectivamente aos termos, encontrados em Sêneca, "voluptas" e "gaudium". Todavia, Hadot entende que Foucault teria cometido um deslize ao interpretar a alegria ou o bom sentimento como outra forma de prazer, pois, de acordo com Hadot, nos estoicos a distinção entre prazer e alegria não corresponde a uma mera questão de vocabulário. Assim, o texto busca recontextualizar a crítica que Hadot dirigiu às análises de Foucault acerca da terapia das paixões no estoicismo, através da problematização da maneira pela qual cada um dos autores compreende a relação entre a alegria e a tranquilidade d'alma. PALAVRAS-CHAVE: Hadot. Foucault. Prazer. Alegria. Felicidade.

\section{ABSTRACT}

According to Hadot, Foucault had transformed the stoic moral in an ethic that seeks pleasure in itself, since he would have erroneously conceived happiness as a state of pure physical and mental pleasure. Hadot affirms that for the Stoics the pursuit of happiness is unconditional

\footnotetext{
* Doutoranda pelo Programa de Pós-Graduação em Filosofia da UFPR (Bolsista CAPES). E-mail: cassianastephan@yahoo.com.br.
} 
and the tranquility of the soul must be understood as an undisturbed state in which the self is stripped of any kind of feeling, be it violent or serene. Differently, Foucault conceives that the domain of the self corresponds to the sovereignty exercised over the self and is linked to a kind of satisfaction that we can have with ourselves. The state of ataraxia or euthumía is interpreted by Foucault as another form of pleasure that is the opposite to the violent pleasures whose origin is not in ourselves, but in the objects to which we wildly assign moral values. Foucault links this distinction between the bad and the good pleasure respectively to the terms found in Seneca, "voluptas" and "gaudium". However, Hadot believes that Foucault would have made a mistake when he interpreted the joy or the good feeling as another form of pleasure because, according to Hadot, for the Stoics the distinction between pleasure and joy does not correspond to a mere matter of vocabulary. Therefore, in this text we aim at recontextualizing the criticisms that Hadot directed towards Foucault's analyzes regarding the therapy of the passions in the Stoicism, by questioning the way in which each author understands the relationship between the joy and the peace of the soul.

KEYWORDS: Hadot. Foucault. Pleasure. Joy. Happiness.

\section{A felicidade e a supressão do prazer}

Segundo Pierre Hadot, a felicidade estoica corresponderia a um estado da alma que é vivenciado através do distanciamento em relação à corporeidade e às sensações de prazer e dor que se atrelariam à subjetividade, a qual se constituiria em virtude da incidência do tempo e do espaço sobre a matéria. Nesse sentido, a felicidade seria experimentada mediante a presença do Divino na alma e em decorrência do amor puro pelo Bem, ou seja, ela concerniria a um estado no qual a alma se desprenderia das vontades e das repulsas relativas ao regozijo e à dor corporal. Por conseguinte, a conquista da felicidade estaria vinculada à purificação da vontade dos homens e à desconstituição da individualidade egoísta, já que este belo estado psíquico resultaria da concordância com o Destino ou com a Razão Universal.

E nós encontramos nos estoicos o mesmo paradoxo que encontramos em Aristóteles e Plotino: Deus é ao mesmo tempo nós mesmos, na medida em que nós somos uma faísca ou um fragmento dele, e qualquer coisa que é mais do que nós mesmos, em direção a qual nós devemos nos voltar, uma norma, uma Razão interior e transcendente, conforme a qual nós devemos viver. (HADOT, 2010, p. 332, tradução nossa). 
Portanto, para Pierre Hadot as interpretações de Foucault acerca das práticas filosóficas da Antiguidade transformariam a felicidade estoica em uma experiência egoisticamente prazerosa, ou seja, Hadot parece propor que para Foucault a felicidade seria adquirida na ocasião da constituição de uma individualidade que buscaria se conformar aos exageros egocêntricos do prazer e da toalete. Sendo assim, de acordo com Hadot, Foucault teria atribuído à ataraxia estoica um caráter hedonista e um aspecto somático que não lhe concerniriam.

De fato, para Pierre Hadot a felicidade estoica não poderia ser vivenciada como uma retenção de prazer que atravessaria tanto os recônditos da alma quanto a superfície do corpo, pois "é notável que, na tradição socrática, o estoicismo representa, por sua vez, um esforço admirável para purificar ao máximo a intenção moral de toda motivação exterior ao amor pelo Bem, de todo hedonismo, mesmo espiritual.” (HADOT, 2010, p. 332, tradução nossa) Com efeito, isso não significa que a alma feliz se encontra destituída de qualquer tipo de sensação, já que, conforme Pierre Hadot, a felicidade se articularia à experiência da alegria (khára), a qual condiz a um sentimento pacífico que se alastra na alma quando esta comunga com o Divino:

\begin{abstract}
Os seres vivos experimentam a alegria quando realizam a função para a qual foram feitos e agem de acordo com a sua própria natureza. Como pudemos ver, o homem realiza sua função qua homem, e segue tanto a sua própria natureza quanto a Natureza universal, quando consente à ordem: a ordem do universo como fixada pelo Destino; a ordem da Cidade do Mundo e dos seres humanos, baseada na atração mútua entre os seres racionais e, por isso, na própria natureza da humanidade; finalmente, a ordem do discurso, o qual reproduz a relação que a Natureza estabeleceu entre as substâncias e os atributos e, acima de tudo, entre os eventos que necessariamente se seguirão um após o outro. Sendo assim, praticando estas três disciplinas, o homem segue a Natureza e encontra a alegria [...]. (HADOT, 2001b, p.239, tradução nossa).
\end{abstract}

Deveras, a alegria não consiste naquilo que motiva a dedicação à sabedoria, isto é, Hadot concebe que para o estoicismo a consagração à moralidade é incondicional. Mais precisamente, a alegria se vincularia à felicidade enquanto um subproduto ${ }^{1}$ desta realização,

\footnotetext{
${ }^{1}$ De modo geral, de acordo com os estoicos, o prazer nos animais concerniria a um subproduto que poderia se vincular à realização do impulso de autopreservação, ao passo que a alegria nos homens consistiria em um subproduto da busca pela felicidade. Isso quer dizer que o prazer e a alegria seriam sensações que ocorreriam após a realização daquilo que é próprio à constituição de cada indivíduo no cosmos. Existem outras formas de conceber a relação entre os impulsos de autopreservação e o prazer ou a busca da felicidade e a alegria, pois estes são assuntos que ensejavam debates no interior da própria escola estoica e que continuam a suscitar discussões entre historiadores da filosofia. De qualquer maneira, Malcolm Shofield nos explica que "Epicuro alegava que não há necessidade nem mesmo de argumentar ou discutir por que o prazer deve ser perseguido e a dor, evitada: basta tão somente apontá-lo. Mas ele argumentava em prol da alegação: da observação de que todos
} 
pois o bem moral é para "si mesmo a sua própria recompensa." (HADOT, 2010, p.333, tradução nossa) Desse modo, Hadot compreende a tranquilidade d'alma como um estado no qual o si mesmo não possui nenhum tipo de sentimento, seja ele bom ou mau. Os maus sentimentos (páthei) não são experimentados pela alma aperfeiçoada e o bom sentimento (eupáthos) não é vivenciado pelo si mesmo porque, segundo Hadot, a alegria não consiste em um estado adquirido por e pelo si mesmo: "Sêneca não encontra sua alegria em Sêneca, mas transcendendo Sêneca, descobrindo que ele tem em si uma razão, parte da Razão universal, interna a todos os homens e ao cosmos em si mesmo." (HADOT, 1993, p.325, tradução nossa). Em outras palavras, para Hadot o estado de ataraxia não estaria atrelado ao si mesmo, mas sim à perda de si mesmo, o qual deve se desconstituir enquanto materialidade em virtude de uma constituição transcendental que desfaz a subjetividade através da identificação entre o logos humano e o logos Divino. Portanto, "Sêneca não encontra mais sua alegria em Sêneca, mas no Sêneca identificado à Razão Universal.” (HADOT, 2001, p.216, tradução nossa).

Logo, a alegria consistiria em uma sensação que nem sempre seria compartilhada com o corpo. A experiência da alegria dependeria da depuração da materialidade ou da radical indiferença em relação aos desejos e às repulsas corpóreas. Nesse sentido, a felicidade corresponderia a um estado vivenciado prioritariamente pela alma que se converte à sua própria natureza quando se une à Razão Universal. Por certo, a terapia das paixões constituiria uma característica importante dos exercícios espirituais, e esta se vincularia à colaboração entre a prática filosófica e a preocupação médica. Talvez possamos afirmar que, conforme Pierre Hadot, a medicina era importante para a pedagogização do si mesmo e para a salvação da alma na medida em que ela prescrevia a moderação às necessidades do corpo. Mais precisamente, parece que para Hadot a medicina contribuía para a minimização da

os animais, tão logo nascem - antes da natureza poder ser corrompida -, buscam o prazer e dele desfrutam como o maior bem, evitando a dor como o maior mal que lhes pode suceder. [...] Crisipo, evidentemente, tinha por imperativo solapar a estratégia epicurista. [...] Segundo Diógenes Laércio (VII 85-6), ele argumentara, no livro I de seu tratado, que os primeiros impulsos dos animais estão voltados não para o prazer, mas para a autopreservação: em primeira instância, eles se identificam à sua constituição e à consciência que dela possuem. É por isso que eles rejeitam o que lhes é nocivo e aceitam aquilo com que têm afinidade. O que os bebês sentem é necessidade de nutrição - é por isso que eles querem o seio da mãe, não porque gostam da alimentação e da sensação de estômago cheio que daí lhes sobrevém. O prazer é meramente um subproduto que pode ocorrer quando se atinge o que convém à constituição do animal [...]” (SHOFIELD, 2006, p. 274). No que tange à alegria, talvez possamos afirmar que ela é uma espécie de prazer, distinta dos prazeres violentos atrelados à estultícia, que necessariamente sobrevém aos exercícios direcionados à felicidade, ou seja, as transformações éticas, sejam elas drásticas ou singelas, são seguidas da alegria. Nesse sentido, Ted Brennan afirma que "os estoicos não precisam negar que o prazer é caracteristicamente sentido como alguma coisa: eles simplesmente argumentam que a tonalidade do sentimento não produz nada e, portanto, não merece seu nome. Comentando a teoria epicurista do prazer (claramente uma teoria não-cognitivista), os estoicos afirmam que 'este prazer - se se trata de um prazer - é um epifenômeno (epigénnema) que surge quando uma natureza busca o que é conveniente a sua constituição e tem êxito em adquiri-lo'.” (BRENNAN, 2006, p. 307). 
interferência material sobre o aperfeiçoamento da alma. O conhecimento médico deveria ser difundido entre os estudantes de filosofia, pois ele desencadearia a percepção de que o corpo, o prazer e a dor são totalmente dispensáveis à conquista da felicidade: "praticaremos exercícios comuns à alma e ao corpo, 'caso nos acostumemos ao frio, ao calor, à sede, à fome, à frugalidade da alimentação, à dureza da cama, à abstinência das coisas agradáveis, a suportar as coisas penosas.” (HADOT, 1999, p.272). Desse modo, a medicina corroborava com a filosofia ao demonstrar que as fortunas ou infortúnios atrelados ao corpo não passavam de provações à alma que se dedica à sabedoria, ou seja, os prazeres e dores enfrentados pela materialidade correspondiam a projetos do Destino cuja finalidade consistia em encetar os indivíduos no caminho da virtude. Sendo assim, as regras dietéticas e eróticas que seriam prescritas em referência ao conhecimento do corpo perspectivavam a condescendência à vontade divina, já que incitavam o corpo a suportar as dores e a abster-se dos prazeres, pois a fuga em relação à dor poderia ensejar a covardia moral, ao passo que a busca pelo prazer poderia desencadear os excessos e vícios que estariam atrelados a uma consciência torpe do si mesmo, isto é, ao individualismo egoísta:

[...] não querer que isso que acontece não aconteça, mas querer que isso que acontece aconteça como acontece. (...) Esse princípio da disciplina do desejo não faz obstáculo à disciplina da ação, ao dever de mudar as coisas humanas ou físicas, quando elas devem ser modificadas, e de agir a serviço da comunidade humana. Mas ele implica também que se saiba que o Destino pode fazer obstáculo a esta ação. E ainda assim é preciso consentir ao Destino, querer que isto que acontece aconteça como acontece, pois o que conta é, enquanto parte do Todo, colaborar com a obra do Todo. É precisamente este consentimento que assegura a serenidade interior, sem a qual jamais haveria uma ação verdadeiramente eficaz. Esta liberdade da ação humana é integrada pela Razão universal ao entrelaçamento das causas. (HADOT, 2000, p.73 e 74, tradução nossa).

\section{A alegria estoica e o esforço autárquico}

Foucault interpretou a felicidade estoica como um estado no qual o si mesmo vivencia outra forma de prazer, ou seja, a alegria se distingue dos prazeres violentos que normalmente incidem sobre a alma e o corpo do indivíduo estulto, o qual não dispõe de uma atitude crítica em relação a si mesmo e, por este motivo, é incapaz de perceber e admitir que necessita de cuidados terapêuticos.

E nisso, essa espécie de prazer pode opor-se, traço por traço, ao que é designado pelo termo voluptas; este designa um prazer cuja origem deve ser colocada fora de nós mesmos e nos objetos cuja presença não nos é assegurada [...]. A essa espécie de 
prazeres violentos, incertos e provisórios, o acesso a si é suscetível de substituir uma forma de prazer que, na serenidade e para sempre, se tem consigo mesmo. 'Disce gaudere, aprende a alegria', diz Sêneca a Lucílio.” (FOUCAULT, 2011b, p. 71).

Foucault associa a felicidade à satisfação que se tem consigo mesmo no momento do exercício da autarquia. Com base nisso, poderíamos admitir que a felicidade concerniria a um estado psíquico e corpóreo cuja experiência se articularia à circunstância na qual o indivíduo exercitaria a crítica e, nesse sentido, o domínio de si. Em outras palavras, a felicidade não corresponderia a um estado de alma pleno e eterno que se vincularia à ascensão metafísica do si mesmo. Logo, talvez pudéssemos propor a hipótese de que para Foucault a felicidade emerge no interstício da subjetivação da verdade que busca subverter os códigos morais e transgredir os limites institucionais. Desse modo, a alegria vivenciada na ocasião da crítica corresponderia à sensação de serenidade que se segue ao dispêndio da força transformadora inerente aos discursos verdadeiros, já que "Sêneca não tem por objetivo acrescentar aos princípios teóricos uma força coercitiva proveniente doutro lugar, mas sim transformá-los em uma força vitoriosa. Sêneca deve possibilitar que a verdade se exerça como uma força" (FOUCAULT, 2013, p. 48, tradução nossa). Sendo assim, a felicidade parece corresponder à sensação prazerosa de serenidade que decorre da vitória da verdade sobre o si mesmo e sobre as relações que este estabelece com o mundo.

Para Foucault os discursos verdadeiros são mais do que um saber teórico acerca da natureza, ou melhor, essas verdades são forças na medida em que incidem sobre o corpo e a alma dos sujeitos de maneira a transfigurá-los, mas também na medida em que resistem às verdades e poderes que fixam normas práticas ou padrões de vida em determinada sociedade e cultura (FOUCAULT, 2010, p. 87). Mais precisamente, as verdades são forças porque ensejam um estilo de viver que se constitui, ao mesmo tempo, como uma alternativa ética e uma resistência política. A intensificação da força que se atrela aos discursos verdadeiros depende, no caso de Foucault, de relações mundanas, as quais são capazes de aguçar a criticidade do indivíduo em relação à circunstância social e cultural na qual se encontra, pois desencadeiam a vivência da multiplicidade do cosmos. O esforço autárquico inerente à subjetivação dos discursos verdadeiros e à dessubjetivação dos padrões e hábitos impostos pelas instituições vigentes na sociedade tem como objetivo transformar a alma e o corpo dos indivíduos para que estes possam enfrentar com soberania as adversidades do Destino. Desta maneira, Foucault também concebe que a alegria não se refere àquilo que motiva a busca pela 
virtude, ou seja, a alegria corresponderia à sensação de um prazer brando que percorreria o corpo e a alma como um subproduto da tensa exercitação da autarquia.

Sendo assim, a partir dessas considerações, somos capazes de perceber que as inquietações de Pierre Hadot no que concerne às análises foucaultianas sobre a felicidade estoica não se vinculam simplesmente aos supostos deslizes filológicos de Foucault, o qual não teria atentado para a antiga distinção conceitual entre o prazer (hédonê) e a alegria (khára) (HADOT, 2001a, p. 216). Talvez possamos presumir que a crítica empreendida por Pierre Hadot no que tange às interpretações de Foucault sobre a alegria estoica se articula, sobretudo, ao estatuto ético do si mesmo e, por conseguinte, ao caráter dialógico da filosofia. Por um lado, Foucault concebe que a sensação de tranquilidade emerge no si mesmo, na alma e no corpo que se transformam eticamente neste mundo. Por outro lado, Pierre Hadot propõe que a tranquilidade concerne a uma experiência exclusiva da alma que se une à Razão Universal quando se separa transcendentalmente da materialidade que a rebaixa e a impede de vislumbrar o seu vínculo fundamental com o Todo. De fato, a maneira pela qual Michel Foucault e Pierre Hadot compreendem o caráter da transformação ética do si mesmo nos permite perceber que existem divergências filosóficas entre ambos no que concerne à experiência da alegria e da relação filosófica com o outro. Nesse sentido, parece que aquilo que incomodou Pierre Hadot corresponde principalmente à forma pela qual Foucault interpretou, sob o viés das técnicas de si, a grandeza d'alma ou a ultrapassagem de si na filosofia estoica. Orazio Irrera (2010, p. 996-997, tradução nossa) nos explica que

\begin{abstract}
contra a tentativa de responder à crise da modernidade sob viés individualista, Hadot tenta sugerir um exercício de sabedoria, sempre frágil e renovado, capaz de 'realizar a integração do $E u$ no mundo e no universo'. Torna-se, então, claro como Hadot considerou importante a dimensão universalista e cósmica sobre a qual - Hadot alegou - Foucault não insistiu suficientemente. A maior parte de sua crítica à concepção foucaultiana da ética antiga se desenvolve nesta perspectiva.
\end{abstract}

Efetivamente, Pierre Hadot e Michel Foucault associam a felicidade à alegria ou à tranquilidade. Além disso, para ambos a felicidade decorre de um processo terapêutico que se refere à antiga aproximação entre filosofia e medicina. ${ }^{2}$ Todavia, faz-se importante ressaltar

\footnotetext{
2 "Esse vínculo entre medicina e cuidado de si, [vínculo] ao mesmo tempo antigo, tradicional, bem estabelecido e sempre repetido, é marcado de diferentes maneiras. É marcado, primeiramente, pela identidade do quadro conceitual entre medicina e filosofia. [...] Mais interessante, sem dúvida, é o fato de que a própria prática de si, tal como a filosofia a define, designa e prescreve, é concebida como uma operação médica." (FOUCAULT, 2010, p.89). Confira também Foucault (2011b, p. 59-63).
} 
que o vínculo entre medicina e filosofia não desencadeia, no caso das interpretações de Michel Foucault, a desvalorização do corpo e a supervalorização da alma. Decerto, Foucault compreende que para os estoicos o corpo é um indiferente, já que os sofrimentos e prazeres que o atingem são incapazes de incidir diretamente sobre a transformação moral dos indivíduos, ou seja, esses sentimentos não correspondem a verdadeiros males ou a verdadeiros bens. Porém, em distinção a Pierre Hadot, Foucault não parece conceber que o corpo seja dispensável à felicidade, pois ele percebe que em certa medida, para os estoicos, o corpo e a alma podem se comunicar e se interferir mutuamente: “é que o ponto no qual se presta atenção nessas práticas de si é aquele em que os males do corpo e da alma podem comunicarse entre si e intercambiar seus mal-estares: lá onde os maus hábitos da alma podem levar a misérias físicas enquanto que os excessos do corpo manifestam e sustentam as falhas da alma" (FOUCAULT, 2011b, p. 62). Nesse sentido, para Foucault a aproximação entre a filosofia e a medicina introduz o corpo na dimensão do cuidado de si. Portanto, a dietética e a erótica concerniriam a práticas médicas que vislumbrariam o bem-estar do corpo em virtude da aquisição e da manutenção do domínio de si mesmo. O exercício da autarquia corresponderia a uma atitude que perpassa simultaneamente a alma e o corpo, ou melhor, tanto o corpo quanto a alma estariam sob o domínio daquele que decide governar a si mesmo. Sendo assim, a única autoridade capaz de ensejar a obediência às regras dietéticas, eróticas e morais concerne ao indivíduo que se vincula autarquicamente a si, aos outros e ao mundo. Logo, para Foucault a alegria seria vivenciada mediante a realização da tarefa que conduz os indivíduos à criticidade filosófica, ou seja, a alegria decorreria da aquisição e da garantia da liberdade:

Essa relação consigo, que constitui o termo da conversão e o objetivo final de todas as práticas de si, diz respeito ainda a uma ética do domínio. Entretanto, para caracterizá-lo não basta invocar uma forma agonística de uma vitória sobre as forças difíceis de domar e de uma dominação capaz de ser exercida sobre elas sem contestação possível. Essa dominação é pensada frequentemente através do modelo jurídico da posse: pertencer 'a si', ser 'seu' (suum fieri, suum esse, são expressões que voltam sempre em Sêneca); somente é de si mesmo que se depende, é-se sui juris; nada limita nem ameaça o poder que se exerce sobre si: detém-se a potestas sui. Mas através dessa forma, antes de mais nada política e jurídica, a relação consigo é também definida como uma relação concreta que permite gozar de si como que de uma coisa que ao mesmo tempo se mantém em posse e sob as vistas. [...] E a experiência de si que se forma nessa posse não é simplesmente a de uma força dominada, ou de uma soberania exercida sobre uma força prestes a se revoltar; é a de um prazer que se tem consigo mesmo. (FOUCAULT, 2011b, p.70). 
De acordo com Foucault, a alegria concerne ao deleite que se atrela à liberdade, a qual se constitui como um exercício árduo que envolve a problematização de si mesmo e do mundo, a subjetivação dos discursos verdadeiros e a resistência aos padrões, hábitos e códigos que impedem a experiência da autarquia. Nesse sentido, talvez pudéssemos propor que Foucault associa a felicidade ao exercício do governo de si mesmo, ao passo que Hadot vincula a felicidade à descoberta da igualdade. Dessa maneira, parece que para Foucault a felicidade se constitui como uma disposição ética e política, pois a alegria corresponderia à satisfação que se segue da mudança no que concerne ao modo de viver e da transformação relativa à forma pela qual o si mesmo age neste mundo. Portanto, a felicidade seria a experiência que se articularia à vida estilizada e à paixão política, na medida em que o filósofo é o esteta que percorre as multidões de modo a inserir-se na pluralidade do mundo. Sendo assim, para Foucault a felicidade não poderia ser compreendida como um estado metafisicamente permanente que seria desfrutado igualmente por todos aqueles que se unem ao Divino. A alegria que se tem consigo seria um sentimento peculiar e circunstancial, pois a felicidade se vincularia à autarquia cujo exercício é atinente a determinada ocasião, ou seja, a certo tempo e a certo espaço que incidem singularmente sobre o sujeito. Isso significa que, de acordo com as interpretações de Foucault, todos podem atingir a felicidade, mas esta experiência não será galgada da mesma forma pelos indivíduos que se dedicam ao cuidado de si e, por conseguinte, não desembocará em uma significação universal da alegria ou da serenidade. A felicidade é uma construção que se vincula à elaboração ética do si mesmo e à resistência política do indivíduo que, ao subverter os códigos morais e transgredir as instituições sociais, vivencia outra forma de prazer, ou seja, um prazer que se constituía como uma experiência até então impossível ou inacreditável. Logo, para Foucault a felicidade não estaria atrelada à esperança em um mundo transcendente, mas à urgência de transformar, na imanência, este mundo.

Pierre Hadot concebe que a felicidade, assim como compreendida por Michel Foucault, seria egoisticamente prazerosa, pois a dominação de si corresponderia à máxima retenção de prazer. Sendo assim, a relação com o mundo e com os outros estaria subordinada a uma vontade impura que prescreveria a busca ambiciosa pelo deleite do si mesmo. Nesse sentido, para Hadot, Foucault empreenderia uma leitura utilitarista da ética antiga porque desconsideraria a influência do conhecimento cosmológico sobre o aperfeiçoamento ético dos indivíduos. Mais precisamente, Foucault teria refletidamente ignorado o fato de que a ultrapassagem de si fundamenta a terapia das paixões. Dessa maneira, as interpretações de 
Foucault acerca da ética estoica recairiam em individualismo, pois obliterariam o caráter dialógico dos antigos exercícios filosóficos, os quais, segundo Hadot, paulatinamente estabeleciam a essencial comunicação entre o si mesmo e o Divino. De fato, para Hadot a vida consagrada à filosofia se fundamenta no amor pela Natureza Universal, de tal maneira que o afeto pelos outros seres racionais corresponderia à manifestação do Divino na alma daquele que busca pelo Bem. Entretanto, seria interessante problematizar e recontextualizar esta crítica proposta por Hadot, já que Michel Foucault também parece conceber que a felicidade depende da interação entre o si mesmo e o outro, isto é, para Foucault a relação com o outro faria parte do cotidiano daqueles que se dedicam ao governo de si mesmos. Com efeito, segundo Foucault, a alegria que se tem consigo não corresponderia a um sentimento egoísta, já que a paixão política e a vida estilizada seriam despertadas na ocasião do amor ou da amizade e, por conseguinte, compartilhadas na instância da sociabilização.

Por certo, Foucault privilegia os exercícios de auto-subjetivação, os quais manifestam a relação entre criticidade e autarquia, ao interpretar a filosofia antiga por meio da estética da existência. Contudo, isso não significa que Foucault tivesse desconsiderado a importância do cosmos para os exercícios filosóficos e, assim como supõe Hadot, transformado o si mesmo em fundamento ético. Pelo contrário, Foucault parece dedicar especial atenção à articulação helenístico-romana entre o si mesmo e o cosmos justamente porque percebe a dimensão social do conhecimento cosmológico no cinismo e no estoicismo, pois para estas filosofias a sociabilidade permite que o indivíduo adquira uma perspectiva mais detalhada do seu lugar no mundo. Talvez seja possível afirmar que, através de sua análise do cosmopolitismo helenístico-romano, Foucault se afaste das interpretações que unem e diluem o si na totalidade, as quais estariam atreladas às conversões do cuidado de si platônico, neoplatônico e cristão. ${ }^{3}$ De acordo com Foucault, no período helenístico-romano o cuidado de si "constituiu, assim, uma prática social, dando lugar a relações interindividuais, a trocas e comunicações e, até mesmo, a instituições" (FOUCAULT, 2011b, p. 50). Por conseguinte, parece que Foucault compreende a dimensão social dos exercícios cínicos e estoicos como

\footnotetext{
${ }^{3}$ Para Foucault, a conversão platônica ou neoplatônica é um ato de reminiscência transcendental e circular: "[...] ter acesso à verdade é ter acesso ao próprio ser, acesso este em que o ser ao qual se tem acesso será, ao mesmo tempo e em contraponto, o agente da transformação daquele a que ele tem acesso. É este o círculo platônico ou, em todo caso, o círculo neoplatônico: conhecendo a mim mesmo, acedo a um ser que é a verdade, e cuja verdade transforma o ser que eu sou, assimilando-me a Deus. A homoíosis tô theô aí está presente." (FOUCAULT, 2010, p. 173). Já a conversão cristã consiste em um ato de retorno a si cuja finalidade é a renúncia de si mesmo: "a renúncia a si é um dos eixos fundamentais do ascetismo cristão. Quanto à mística cristã, sabemos que também ela, se não inteiramente comandada, absorvida, é pelo menos atravessada pelo tema do eu que se aniquila em Deus, perdendo sua identidade, sua individualidade, sua subjetividade em forma de eu, por uma relação privilegiada e imediata com Deus" (FOUCAULT, 2010, p. 224).
} 
uma maneira de percorrer o cosmos e de realizar a vida conforme a natureza. Se o conhecimento da natureza for assim interpretado por Foucault, então o acesso ao cosmos, por oposição a Pierre Hadot, não corresponderá a uma atividade transcendental. Desse modo, talvez seja possível afirmar que Foucault, ao se afastar da cosmologia unitiva e divinizadora desenvolvida por Hadot, nos conduz, a partir do acesso social ao cosmos, a uma percepção plural da totalidade.

Com base nestas considerações, acreditamos que o atual estudo nos remete à interrogação concernente à maneira pela qual Foucault e Hadot articulam a experiência estética do amor ou da amizade à ética e à política e, desse modo, compreendem a relação entre os indivíduos e a comunidade social, e isso não só no que tange aos antigos, mas também no que se refere às implicações filosóficas da estética da existência e dos exercícios espirituais no tempo presente. Levando em consideração as implicações contemporâneas das reflexões de Hadot e de Foucault sobre a filosofia dos antigos, pretendemos, em pesquisa futura, discutir a hipótese de que (1) a Razão Universal corresponderia, no caso de Pierre Hadot, ao fundamento moral de uma comunidade operante, organizada e mantida por meio de poderes cuja autoridade é consagrada à legitimidade institucional de saberes sobre a condição humana; e de que (2) a autarquia estética, no caso de Michel Foucault, poderia ensejar a constituição de diversas e fugidias coexistências sociais, estimuladas pela experiência éticopolítica de amizades ou de amores anárquicos, isto é, de vínculos afetivos que se pretendem resistentes à operância institucional e normalizadora dos poderes, os quais se exercem em articulação a saberes que esperam consolidar cabalmente a verdade sobre a natureza humana. Nesse sentido, gostaríamos de problematizar as diferenças entre duas perspectivas acerca da convivência social para, subsequentemente, interrogar o teor das tensões políticas que estas concepções desencadeariam no âmbito de sua efetividade prática.

\section{REFERÊNCIAS}

BRENNAN, T. Psicologia moral estoica. In: INWOOD, B (Org.). Os estoicos. Tradução de Paulo Fernando Tadeu Ferreira e Raul Fiker. São Paulo: Odysseus, 2006, p. 285-327.

ÉPITÈTE. Manuel d’Épictète. Tradução de Pierre Hadot. Paris: Livre de Poche, 2000.

FOUCAULT, M. A hermenêutica do sujeito. Tradução de Márcio Alves da Fonseca e Salma Tannus Muchail. São Paulo: Martins Fontes, 2010.

FOUCAULT, M. A coragem da verdade. Tradução de Eduardo Brandão. São Paulo: Martins Fontes, 2011a. 
FOUCAULT, M. A história da sexualidade 3: O cuidado de si. Tradução de Maria Thereza da Costa Albuquerque. São Paulo: Graal, 2011b.

FOUCAULT, M. Dits et écrits II. 1976-1988. Paris: Gallimard, 2001.

FOUCAULT, M. L’origine de l'herméneutique de soi. Paris: Vrin, 2013.

FOUCAULT, M. ¿Qué es la crítica?. Daímon: Revista de Filosofia. Tradução de Javier de la Higuera, 1995, p. 5-25.

HADOT, P. Études de Philosophie Ancienne. Paris: Les Belles Letres, 2010.

HADOT, P. Exercices spirituels et Philosophie Antique. Paris: Albin Michel, 1993.

HADOT, P. La Philosophie comme manière de vivre: entretiens avec Jeannie Carlier et Arnold I. Davidson. Paris: Albin Michel, 2001a.

HADOT, P. O que é a filosofia antiga? Tradução de Dion Davi Macedo. São Paulo: Edições Loyola, 1999.

HADOT, P. The Inner Citadel: The meditations of Marcus Aurelius. Tradução de Michael Chase. Cambridge: Harvard University Press, 2001b.

IRRERA, O. Pleasure and transcendence of the self: Notes on "a dialogue too soon interrupted" between Michel Foucault and Pierre Hadot. Boston, Philosophy and Social Criticism, 2010, p. 995-1017.

SCHOFIELD, M. Ética estoica. In: INWOOD, B (Org.). Os estoicos. Tradução de Paulo Fernando Tadeu Ferreira e Raul Fiker. São Paulo: Odysseus, 2006, p. 259-284. 